\title{
Distribution of Four Viruses in Single and Mixed Infections Within Infected Watermelon Plants in Florida
}

\author{
William W. Turechek, Chandrasekar S. Kousik, and Scott Adkins
}

First and third authors: United States Department of Agriculture-Agricultural Research Service (USDA-ARS), U.S. Horticultural Research Laboratory, 2001 South Rock Road, Fort Pierce, FL 34945; and second author: USDA-ARS, U.S. Vegetable Laboratory, 2700 Savannah Highway, Charleston, SC 29414.

Accepted for publication 23 June 2010.

\begin{abstract}
Turechek, W. W, Kousik, C. S., and Adkins, S. 2010. Distribution of four viruses in single and mixed infections within infected watermelon plants in Florida. Phytopathology 100:1194-1203.

Whitefly-transmitted Squash vein yellowing virus (SqVYV) and Cucurbit leaf crumple virus (CuLCrV) and aphid-transmitted Papaya ringspot virus type W (PRSV-W) have had serious impact on watermelon production in southwest and west-central Florida in the past 5 years. Tissue-blot nucleic acid hybridization assays were developed for simple, high-throughput detection of these three viruses as well as Cucurbit yellow stunting disorder virus (CYSDV), which was first reported in Florida in 2008. To determine virus distribution within plants, we collected 80 entire plants just before or during the harvest period in a systematic sample, 20 each on 11 April, 18 April, 26 April, and 3 May 2007, from a fruiting commercial watermelon field near Immokalee, FL showing symptoms of infection by SqVYV, CuLCrV, and PRSV-W and, possibly, CYSDV. This was followed by a sampling of five plants collected at harvest showing symptoms of virus infection on 11 October

crowns through the tips at $0.6-\mathrm{m}$ intervals on nylon membranes and nucleic acid hybridization assays were used for virus detection. Results from testing crown tissue showed that SqVYV, CuLCrV, and PRSV-W were present in $\approx 37,44$, and $54 \%$, respectively, of the 80 plants collected over the four sampling dates from the first field. For individual vines diagnosed with SqVYV, the distribution of SqVYV in vine tissue decreased proportionately with distance from the crown. The probability of detecting SqVYV was $70 \%$ at the base of the vine compared with $23 \%$ at the tip of the vine. In contrast, $\mathrm{CuLCrV}$ tended to be more evenly distributed throughout the plant, with $\approx 10 \%$ higher probability of detection at the growing tip relative to the crown of the plant. The distribution of PRSV-W resembled that of SqVYV but with $\approx 20 \%$ higher probability of detection at the tip of the vine. Similar trends were detected in the smaller sampling; however, CYSDV was also detected in three of the plants. Overall, the results indicated that SqVYV and PRSV-W were distributed differently than $\mathrm{CuLCrV}$ in watermelon plants, and this difference has implications on how samples should be collected and may affect vector acquisition and transmission of these viruses.
\end{abstract} 2007 in a different commercial planting located in Duette, FL. Tissue prints were made from cross sections of watermelon plants from the
Additional keywords: epidemiology, Jaccard index.
Florida is one of the leading states in the production of watermelon (Citrullus lanatus Thunb.) and is the sole U.S. supplier of domestic watermelon from December to April (7). During the past 5 years, three whitefly-transmitted viruses have been detected for the first time in cucurbit crops in Florida. The recently characterized Squash vein yellowing virus (SqVYV) is perhaps the most serious of these viruses (2). The virus, first identified in 2005, causes a rapid vine decline in watermelon as the crop approaches harvest. SqVYV is an Ipomovirus sp. within the family Potyviridae and is transmitted by whiteflies (Bemisia tabaci, biotype B). SqVYV is distributed widely in southwest and west-central Florida and has recently been reported from southern Indiana $(2,12)$. Several common cucurbit weeds have been identified as reservoirs for SqVYV $(3,4)$. Crop losses in the 200304 seasons due to SqVYV were 50 to $100 \%$, with monetary losses

Corresponding author: W. W. Turechek;

E-mail address: William.Turechek@ars.usda.gov

The use of trade, firm or corporation names in this publication is for the information and convenience of the reader. Such use does not constitute an official endorsement or approval by the United States Department of Agriculture or the Agricultural Research Service of any product or service to the exclusion of others that may be suitable.

doi:10.1094/PHYTO-01-10-0018

This article is in the public domain and not copyrightable. It may be freely reprinted with customary crediting of the source. The American Phytopathological Society, 2010. to Florida watermelon growers estimated at $\$ 60$ to 70 million U.S. in 2004 alone (15).

In October 2006, Cucurbit leaf crumple virus (CuLCrV) was found infecting yellow straightneck and zucchini squash (Cucurbita pepo L.) plants in central Florida (5). By spring 2007, the virus was discovered in watermelon plantings in Collier and Hendry Counties in southwest Florida, and Hillsborough, Manatee, and Sarasota Counties in west-central Florida (5). CuLCrV was subsequently found in fresh-market common bean plantings (1) and cucurbit weeds $(3,4)$ in southwest Florida. CuLCrV is a Begomovirus sp. and, like SqVYV, is transmitted by whiteflies ( $B$. tabaci). CuLCrV was first identified in cucurbits in the southwestern United States and northern Mexico $(9,14)$.

In summer 2007, a third whitefly-transmitted virus, Cucurbit yellow stunting disorder virus (CYSDV), was found infecting watermelon and squash in several counties in west-central Florida (23) and has subsequently spread into southwest Florida. Similar to SqVYV and CuLCrV, CYSDV was observed infecting a common cucurbit weed in southwest Florida (4). CYSDV was first found in North America in southern Texas and northern Mexico in 1999 (16) and then in Arizona and California in 2006 $(8,17)$. CYSDV is a Crinivirus sp. and is transmitted by both the B and Q biotypes of B. tabaci $(6,21)$.

Managing virus diseases through vector management alone is often difficult $(11,28)$. Additional strategies to manage virus diseases must be sought. As a first step, it is necessary to gain a better understanding of how these viral epidemics develop for 
individual viruses as well as infections by multiple viruses. Characterizing the incidence and within-plant distribution of viruses in single or mixed infections can provide insight and lead to testable hypotheses of viral dynamics, including whitefly acquisition and transmission rates, and provide information that will facilitate sampling efforts and diagnostic testing. The distribution of any single virus within host plants is influenced by interaction of the virus and host, the environment, fitness of the virus strain, and grower management practices. Virus distribution within plants is also influenced by interaction of the virus with other viruses or pathogens. The frequency with which two viruses are found occupying the same niche (e.g., plant, vine, and so on) is a measure of the affinity for coexistence (18). For example, association between two viruses transmitted by the same vector species would be expected if these viruses share a common reservoir host and can be acquired simultaneously by the same individual vector. Conversely, dissociations may result from direct competition (either within the host or the vector), the release of antagonistic compounds such as toxins or pathogenesis-related proteins by the host, or spatial separation within the host, such that the vector cannot easily acquire both viruses during the same feeding event.

A reliable virus detection method is required to analyze sufficient numbers of plant samples to develop the types of epidemiological data described above. Serological assays are routinely used for this purpose due to their economy and specificity (20). Papaya ringspot virus type W (PRSV-W) enzymelinked immunosorbent assay (ELISA) kits are commercially available (Agdia, Inc., Elkhart, IN) but no antibodies for SqVYV, $\mathrm{CuLCrV}$, or CYSDV are commercially available as yet. Detection methods based on polymerase chain reaction (PCR) have been previously reported for all four of these viruses but these techniques are not well suited for large-scale testing, generally due to expense and resource limitations. Tissue-blot nucleic acid hybridization assays are a suitable alternative to ELISA as reported for the SqVYV relative, Cucumber vein yellowing virus (CVYV), because this format is less sensitive to sequence variation than PCR-based techniques, extraction of nucleic acid is not required, and many samples can be processed concurrently (26). Additionally, multiple viruses may be assayed in the same samples by making replica tissue blots.

The objectives of this research were to (i) develop simple and high-throughput tissue-blot nucleic acid hybridization-based detection methods for SqVYV, CuLCrV, PRSV-W, and CYSDV; (ii) characterize the incidence and within-plant distribution of these four viruses in single or mixed infections in plants in two commercial watermelon crops in Florida; and (iii) measure the degree of pairwise association among these four viruses at multiple scales within plants.

\section{MATERIALS AND METHODS}

Virus sources and nucleic acid isolation. The original squash plant isolate of SqVYV and a previously described Florida watermelon isolate of PRSV-W were maintained in squash $(C$. реро) of the cv. Prelude II (Seminis Seeds, Oxnard, CA) in a greenhouse by mechanical transmission using $20 \mathrm{mM}$ sodium phosphate buffer ( $\mathrm{pH} 7.0$ ) containing $0.1 \%$ (wt/vol) sodium sulfite and $1 \%(\mathrm{wt} / \mathrm{vol})$ Celite $(2,3)$. Samples of Florida watermelon plants infected with $\mathrm{CuLCrV}$ or CYSDV were collected from growers' fields. Nucleic acid was extracted from infected leaf tissue with an RNeasy kit (Qiagen, Valencia, CA) following the manufacturer's instructions.

Tissue-blot nucleic acid hybridization assay development. A 1,071-bp product encompassing the 3 '-most portion of the SqVYV NIb gene and the majority of the coat protein (CP) gene was amplified by reverse transcription (RT)-PCR using previously described primers (identical to nucleotides 8,407 to 8,433 and complementary to nucleotides 9,454 to 9,477 of the SqVYV genome; GenBank accession no. EU259611) and conditions (3). An $\approx 1,200$-bp portion of the CuLCrV A component was initially amplified by PCR using previously described degenerate Begomovirus primers (PAL1v1978 and PAR1c496) and conditions (24). Internal primers (5'-CCCCCACGTGGAGAATAGTTA GCA-3' and 5'-CTTCTAGCTCGCACTGGCCGCGCA-3') were then designed from the initial PCR product sequence and used to amplify a 1,096-bp portion of the CuLCrV A component; all subsequent $\mathrm{CuLCrV}$ experiments used this smaller product. A 970-bp portion of the PRSV-W CP gene and 3' untranslated region was amplified by RT-PCR using primer 5'-GACGAT GCTAGTGACGGAAATGAT-3' (identical to nucleotides 126 to 149; GenBank accession no. S89893) and a previously described viral complementary-sense primer and conditions (3). A 753-bp portion of the CYSDV CP gene was amplified by RT-PCR using previously described primers (CYSCPf and CYSCPr) and conditions (25). All PCR products were ligated into pGEM-T (Promega Corp., Madison, WI) and sequenced on an ABI3730XL automated sequencer at the U.S. Horticultural Research Laboratory DNA Sequencing Support Laboratory to confirm the identity of the respective virus.

Digoxigenin (DIG)-labeled cDNA probes were synthesized by PCR amplification from the above-described clones (with the same primer sets used to generate the original clones) using the Roche PCR DIG Probe Synthesis Kit (Indianapolis, IN) following the manufacturer's instructions. Freshly cut sections of infected watermelon stems or squash petioles were pressed onto positively charged 10-by-15-cm nylon membranes (Roche) to make tissue prints for use in verifying the functionality and virus specificity of all four probes. Watermelon stems or squash petioles from known noninfected plants were used to make negative control tissue prints on each of the membranes. Individual cuts were made transverse to the watermelon stem or squash petiole with a new heavy-duty $(0.30-\mathrm{mm})$ single-edge surgical steel razor blade (American Safety Razor Co., Cedar Knolls, NJ). The original clones were also spotted on each of the membranes as further controls. Membranes were allowed to air dry prior to UV crosslinking for $30 \mathrm{~s}$ at $250 \mathrm{~mJ}$ (GS Gene Linker UV Chamber; BioRad, Hercules, CA). Membranes were prehybridized, hybridized with the DIG-labeled cDNA probes, washed, and developed using the DIG Wash and Block Buffer Set, Anti-Digoxigenin-AP Fab fragments, and CDP-Star ready-to-use chemiluminescent reagent (Roche) following the manufacturer's instructions. The membranes were then used to expose x-ray film (generally for 0.5 to $1.5 \mathrm{~h}$ ) to make a permanent record. Film of each membrane was scored by visual comparison of the signal from each sample with that of the appropriate positive and negative controls.

Field sampling of watermelon plants. Eighty entire plants (cv. Tri-X 313; Rogers/Syngenta Seeds, Inc., Boise, ID) were collected over a 4-week period (beginning $\approx 1$ week before fruit harvest and continuing through harvest) from a commercial watermelon field in southwest Florida exhibiting symptoms of SqVYV, CuLCrV, PRSV-W, and, possibly, CYSDV. The field was located near Immokalee, FL in Collier County. Twenty plants were collected at each of the weekly visits on 11 April, 18 April, 26 April, and 3 May, 2007. Plants were collected systematically by establishing a diagonal transect at the southwest corner of a 26-ha block of watermelon plants, collecting a single plant and all attached fruit (but not marking the location of the fruit on the vines), then proceeding $\approx 20 \mathrm{~m}$ to the east (within row) and moving across the rows $7.6 \mathrm{~m}$ to the north (every third row) until the end of the field was reached.

A second, smaller survey was conducted in a commercial watermelon field at the time of first fruit harvest $\approx 3.5 \mathrm{~km}$ west of Duette in Manatee County in west-central Florida. Five entire watermelon plants-three of the cv. Tri-X 313 and two of the "personal" type (cv. Vanessa; Nunhems USA, Parma, ID)—were 
collected arbitrarily from two areas of the field exhibiting symptoms of virus infection on 11 October 2007. The location of all fruit on each vine was marked during collection by wrapping tape around the stem at the point of fruit attachment.

Evaluation of field samples. Vine segments, $\approx 5 \mathrm{~cm}$ long, were cut (as described above) every $0.6 \mathrm{~m}$ from the crowns through the growing tips from each major vine on all watermelon plants, and the freshly cut ends from each segment were pressed onto membranes (gridded for ease of sample tracking) to make tissue blots. The crown tissue, every peduncle found along the vine attached to an immature fruit, and every peduncle on a detached major fruit collected during sampling were similarly used to make tissue blots. In the second survey, juice extracted from intact fruit by poking the rind to a depth of $1 \mathrm{~cm}$ with a new, sterile $1-\mathrm{ml}$ pipette tip was additionally spotted on the membranes. Four replicate membranes were made for each plant to facilitate independent testing for each of the four viruses by nucleic acid hybridization as described above. Appropriate positive and negative controls were included on each membrane and films were scored as indicated above.

Hybridization results for all initial samples and $\approx 10 \%$ of subsequent samples (equal numbers of positive and negative) were confirmed by RT-PCR or PCR using the primer sets described above; additional primers that amplify independent regions of the SqVYV (primer pairs I and J) (4), CuLCrV (AC1048/AV494) (30), or CYSDV (CYShspF/CYShspR) (17) genomes; and commercially available PRSV-W ELISA kits (Agdia, Inc.). As with initial probe development, all RT-PCR and PCR products were cloned and sequenced to verify virus identity.

Virus incidence in watermelon plants. The presence or absence of each virus in the sampled watermelon plants was determined from films of the tissue-blot membranes for all vine segments, crowns, peduncles (proxies for fruit), or fruit (second field only) to determine the distribution of virus within plants. To determine which tissue was the best to assay for establishing the infection status of a plant, the probability of rating a plant positive for a particular virus was calculated for each of the tissue types tested (i.e., crown, vine, fruit, or peduncle tissue). Furthermore, for vines that had at least one segment testing positive, the proportion of vine segments testing positive at each of the $0.6-\mathrm{m}$ intervals was calculated to determine the relationship between virus incidence and distance from the crown, and these relationships were characterized using simple linear regression (Minitab version 15; Minitab Inc., State College, PA).

Statistical analysis of plant-virus associations. The results from the Immokalee survey were used to calculate the incidence of each virus at three hierarchal levels: plant level, vine level, and individual-vine-segment level. Thus, a plant was considered diseased if any of the vines tested positive, and a vine was considered diseased if any individual segment from that vine tested positive. At each hierarchal level, a $\chi^{2}$ test of independence was used to test for pairwise associations for each possible pair of viruses (i.e., SqVYV:CuLCrV, SqVYV:PRSV-W, and CuLCrV:PRSV-W). The same analysis was used to test for association of virus incidence in different plant parts (i.e., crown versus vine, crown versus peduncle, and vine versus peduncle) for the individual viruses. For each comparison, Cramer's $V^{2}$ was used to measure the strength of association for each test (13). Cramer's $V^{2}$ is a $\chi^{2}$-based measure of nominal association and, like most indices of association, ranges from 0 to 1 . The maximum value of 1 can only be achieved when row and column marginals (i.e., the sums of the individual rows and columns) are equal. $V^{2}$ is calculated as $\chi^{2} / n m$, where $n$ is the sample size and $m$ is the smaller of rows -1 or columns -1 . For two-by-two tables, $m=1$.

In addition to the $\chi^{2}$ test of independence, pairwise associations for each possible pair of viruses were quantified using the Jaccard index of similarity $(J)(18)$. The values of the index range from 0 to 1 , where values close to 1 are indicative of a high degree of association and values close to 0 represent dissociation. For each virus pair, the Jaccard index was calculated using $J=a /(a+b+$ $c$ ), where $a$ represents the number of samples in which both viruses occurred, $b$ represents the number of samples in which only the first virus occurred, and $c$ represents the number of samples in which only the second virus occurred. The Jaccard index does not make use of the number of observations for which neither virus was detected. Therefore, the index represents the probability of both viruses being present in the same sample for those samples for which either virus was present.

A nonparametric statistical procedure was used to test the observed value of $J$ against the expected value of $J$ under the null hypothesis of no association (29). In brief, a randomization procedure was developed to derive a sampling distribution for $J$ and the expected value of the index was calculated from this empirical sampling distribution (29). The jackknife procedure was used to estimate the standard error of $J$ under the null hypothesis of no association (19). To test whether the observed Jaccard index was significantly different from the value calculated under the assumption of independence, a normal distribution was assumed for the index estimated by $J$ (the observed Jaccard value) with standard error estimated by the jackknifed value. A standard normal statistic, $Z$, was then calculated. Treating $Z$ as a two-sided test, values of $Z>1.96$ indicate significant positive association and values of $Z<-1.96$ indicate significant negative association or dissociation at $P=0.05$. The Jaccard index was calculated for the comparisons described above and results were compared with the $\chi^{2}$ test results.

\section{RESULTS}

Tissue-blot nucleic acid hybridization assay. SqVYV, CuLCrV, PRSV-W, and CYSDV were each readily detected by tissue-blot hybridization using the DIG-labeled cDNA probes developed for the respective virus (Fig. 1 and data not shown). No cross reaction between viral species was observed. All initial tissue-blot hybridization results (during development of the assay) and selected subsequent results (from plant samples collected in the two fields) were verified by RT-PCR, PCR, or ELISA testing (as described in the Materials and Methods), providing evidence for the reliability of the tissue-blot nucleic acid hybridization technique and probes for specific detection of these four viruses, and for our ability to rapidly determine the relative within-plant distribution of these viruses as described below (Fig. 1).

Virus incidence. The incidence of SqVYV, CuLCrV, and PRSV-W in crown tissue, vines, and peduncles (proxies for fruit) at each sampling date for the field located near Immokalee is shown in Figure 2. CYSDV was not detected in this field. Of the 80 plants tested over the four sampling dates, 37, 44, and 54\% of the crowns tested positive for SqVYV, CuLCrV, and PRSV-W, respectively. The incidence of plants that tested positive for SqVYV was highest during the second sampling period in all tissues and decreased substantially in samplings 3 and 4 for crown tissue and peduncles but not vine tissue (Fig. 2A). The incidence of $\mathrm{CuLCrV}$ in crowns and vine tissue was lowest at the first sampling date and was $\approx 40 \%$ higher for the remaining sampling dates (Fig. 2B). The incidence of PRSV-W in crowns and vine tissue was near $40 \%$ for the first three sampling dates and increased by $\approx 40 \%$ at the remaining sampling date (Fig. $2 \mathrm{C}$ ). The incidence of $\mathrm{CuLCrV}$ and PRSV-W in peduncles generally increased at each sampling except for a small decrease in incidence of both viruses from sampling 3 to 4 (Fig. 2B and C).

For the crop sampled at Duette, only one plant each (but different plants) tested positive for SqVYV and PRSV-W, and three of five plants tested positive for $\mathrm{CuLCrV}$ in at least one tissue (Fig. 3). Only peduncles were tested (as proxies for fruit) in the first field sampled but both peduncles and fruit were tested for 
the Duette field samples to establish whether peduncles were appropriate proxies for fruit. There was a perfect (100\%) correlation of SqVYV detection in peduncles and fruit (i.e., if the peduncle was infected, so was the fruit, and vice versa) (Fig. 1A), supporting the continued use of peduncles as proxies for fruit for SqVYV testing. CuLCrV and CYSDV were only detected in peduncles but not fruit, and PRSV-W was not found in either peduncles or fruit (Figs. 1B and 3). CYSDV was found in the three Tri-X 313 plants tested. CYSDV was absent in the vine tip of 11 of the 15 vines that tested positive and in 7 of 10 peduncles (and all fruit) despite the vine testing positive. CYSDV was not detected in the two Vanessa plants tested (Fig. 3).

For plants with SqVYV detected in their crowns, the distribution of SqVYV in vine tissue decreased with actual and percent distance from the crown (Fig. 4A and B). The calculations were based on the mean of all vines on crown-infected plants; therefore, a proportion of the vines on these plants did not test positive for the specific virus. For SqVYV, $65 \%$ of the vines on crown-infected plants had at least one segment test positive for SqVYV. In crowns that tested negative for SqVYV (63\% of the plants), a similar relationship with distance from the crown was found (Fig. 4C and D). In this case, however, only $18 \%$ of the vines had at least one segment test positive. The slopes of the regression lines characterizing the relationship between virus incidence and distance were significantly negative in both crownpositive and crown-negative plants but the magnitude of the slope in crown-positive plants was approximately four times as large as the slope in crown-negative plants (Table 1). For plants sampled from the Duette crop, this trend was not as pronounced (Fig. 5A and $\mathrm{B}$ ); however, regression analysis showed a significant negative slope for the single SqVYV-infected plant (Table 2).

$\mathrm{CuLCrV}$ was generally uniformly distributed throughout the vine in the $44 \%$ of the plants collected near Immokalee in which

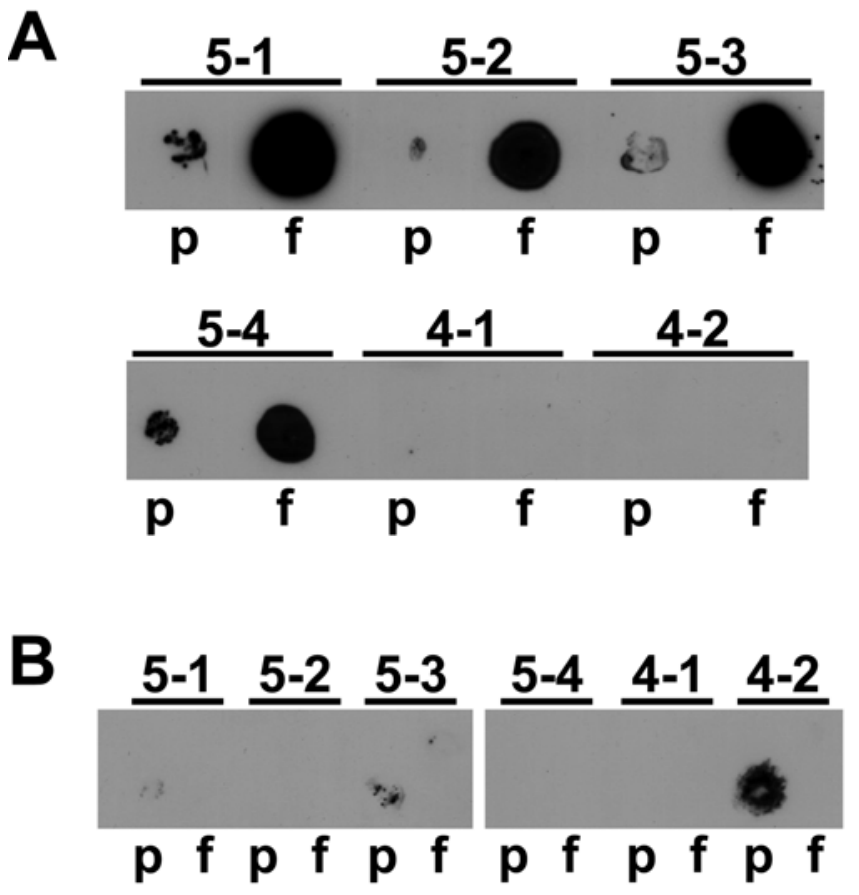

Fig. 1. Representative results of tissue blot nucleic acid hybridization for Squash vein yellowing virus (SqVYV) and Cucurbit leaf crumple virus $(\mathrm{CuLCrV})$ in peduncle (p) tissue prints and fruit (f) juice spots from two plants collected in a commercial watermelon field near Duette, FL. A, SqVYV was detected in both peduncles and fruit juice from all four fruit (5-1, 5-2, 5-3, and 5-4) of plant 5 but in neither peduncles nor fruit juice from the first two fruit (4-1 and 4-2) of plant 4. B, CuLCrV was detected only in peduncles from the first and third (5-1 and 5-3, respectively) fruit of plant 5 and in the peduncle of the second fruit (4-2) of plant 4. the crown tested positive for $\mathrm{CuLCrV}$ and in the $32 \%$ of plants that had at least one vine segment test positive but the crown test negative (Fig. 4C and D). The slope of the regression lines characterizing the relationship between virus incidence and distance was not significantly different from zero in all cases (Table 1). The same trends were found in the more limited number of plants collected at Duette; however, the very small sample size from which the data in Figure 5 was generated makes it difficult to generalize about distribution of each virus in individual plants at this site (Fig. 5A and B).

In all, $54 \%$ of the crowns sampled at the Immokalee field site tested positive for PRSV-W and, of these plants, $57 \%$ of the vines had at least one vine segment test positive (Fig. 4A and B). As with SqVYV, the distribution of PRSV-W in vine tissue generally decreased with increasing distance from the crown; this was particularly evident when distance was measured as a percentage of total vine length (Fig. 4B). However, in terms of actual distance, the incidence of PRSV-W was 20 to $30 \%$ higher than SqVYV in tissue located $>3 \mathrm{~m}$ from the crown tissue. This relationship was also seen in the $13 \%$ of the vines of crown-negative plants that had at least one segment testing positive.

CYSDV was uniformly distributed throughout the vines in the three infected plants diagnosed from the field near Duette, with

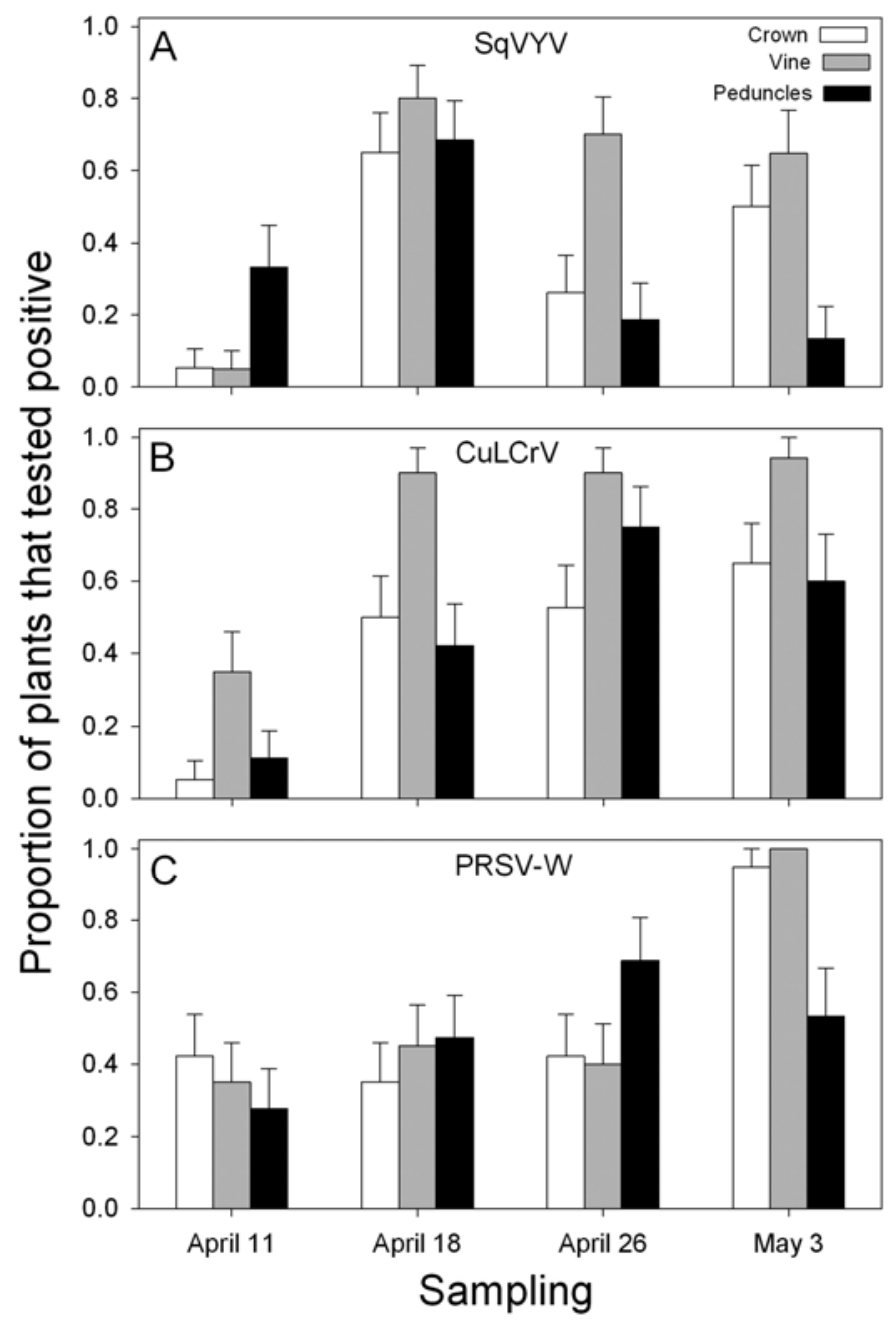

Fig. 2. Incidence of A, Squash vein yellowing virus (SqVYV), B, Cucurbit leaf crumple virus $(\mathrm{CuLCrV})$, and $\mathbf{C}$, Papaya ringspot virus type W (PRSV$\mathrm{W}$ ) in crown tissue, vine tissue, and peduncles at four sampling dates from watermelon plants (cv. Tri-X313) collected from a commercial watermelon field near Immokalee, FL in 2007. A vine was rated as positive if any of the vine segments tested positive. The sampling dates were 11 April, 18 April, 26 April, and 3 May 2007 for 1 through 4, respectively. Error bars are the standard errors of the mean. 
the notable exception of the virus being absent at the tip in 8 of the 11 vines that tested positive on these three plants. Also, only $30 \%$ of the peduncles (and none of the fruit) tested positive on these three plants.

The relationship between virus incidence and distance from the crown was examined in vines that had at least one segment testing positive (regardless of the virus state of the crown) (Fig. 4E and F). The slope of the regression lines characterizing the relationship between virus incidence and actual distance or percentage distance from the crown was significantly negative for SqVYV at both the Immokalee and Duette fields but was not significantly different from zero for CuLCrV at both fields (Tables 1 and 2). For PRSV-W, the results were mixed, with the slope being significantly negative at Immokalee but not at Duette.

Association analysis. The degree of association between SqVYV, CuLCrV, and PRSV-W, as measured through pairwise comparisons, was characterized at the level of the plant, entire vine, and vine segment. At the plant level, a significant pairwise association between SqVYV and CuLCrV was detected for plants rated as positive according to Jaccard's similarity index and
Cramer's $V^{2}$, where a positive rating was given if either the crown tested positive, any vine on a given plant tested positive, or either of the tissues tested positive (i.e., crown or vine) (Table 3). The observed value of the Jaccard index was close to the maximum possible for the given data set (Table 3). No other significant associations were detected at the individual plant level. At the individual vine level, significant associations were found for all pairwise comparisons. The magnitude of the associations was greatest between SqVYV and CuLCrV. At the individual vine segment level, significant pairwise associations were found between SqVYV and CuLCrV and between SqVYV and PRSV-W but not between CuLCrV and PRSV-W. The magnitude of the associations was greatest between SqVYV and $\mathrm{CuLCrV}$ and was slightly lower than that measured at the vine level.

A statistically significant association between the presence of a virus in crown tissue and vine tissue was found for all three viruses according to both the Jaccard index and Cramer's $V^{2}$ (Table 3). For CuLCrV, significant associations were also found for the presence of virus in peduncle and crown tissue, and peduncle and vine tissue. Given the relatively uniform distribution

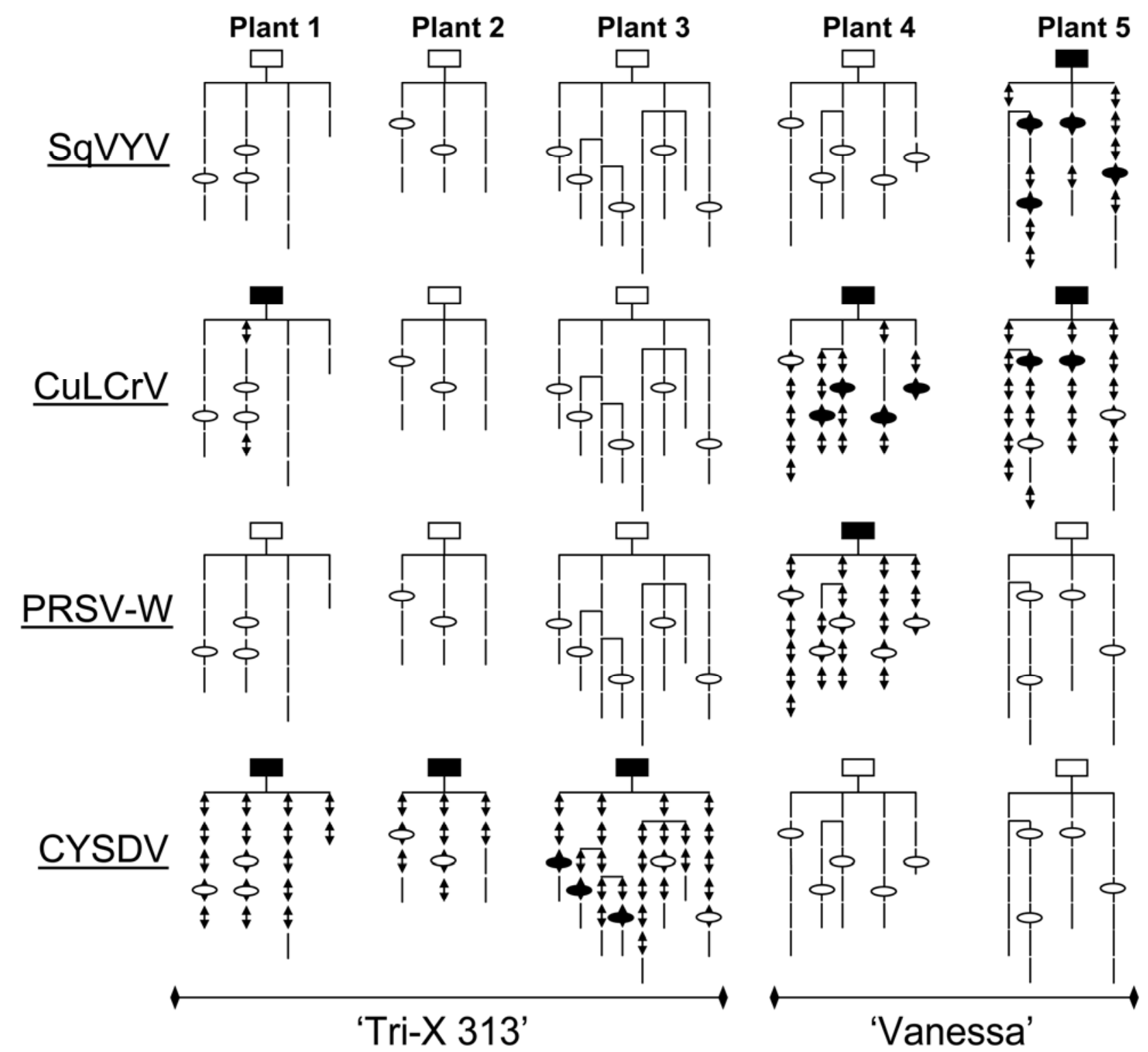

Fig. 3. Schematic representation of the distribution of Squash vein yellowing virus (SqVYV), Cucurbit leaf crumple virus $(\mathrm{CuLCrV})$, Papaya ringspot virus type W (PRSV-W), or Cucurbit yellow stunting disorder virus (CYSDV) in five plants showing symptoms of virus infection collected from two areas of a commercial watermelon field near Duette, FL on 11 October 2007. Rectangles represent crown tissue, ovals represent individual fruit, and the line segments represent 0.6-m segments of vine tissue assayed. Darkened shapes and arrowed-segments indicate the presence of the virus as determined by nucleic acid tissue-blot hybridization. 
of this virus in the watermelon plants assayed in this study, this was not surprising. The association of SqVYV in crown tissue and peduncles was marginally significant according to the $\chi^{2}$ test of independence and marginally insignificant according the randomization test for the Jaccard index $(P=0.05)$. The association of SqVYV in vine tissue and peduncles was marginally insignificant according to both tests. Statistically significant associations were not detected for PRSV-W in crown and peduncles and vine tissue and peduncles.

\section{DISCUSSION}

Accurate identification is the first step in managing a pathogen. The tissue-blot nucleic acid hybridization assays developed in this study for detection of SqVYV, CuLCrV, PRSV-W, and CYSDV made possible simple, high-throughput testing of the large numbers of samples required to develop the epidemiological data for the four viruses evaluated in this study. Although tissue-blot assays lack the sensitivity of PCR-based assays, when used in combination with symptom expression they add a high degree of reliability to a diagnosis. In the absence of symptoms, the tissueblot assay can be used in combination with PCR. The tissue-blot assay would be used to rapidly screen a large number of samples and PCR would be used to confirm positive identification in selected samples.

The distributions of SqVYV, CuLCrV, and PRSV-W were determined by testing 1,534 plant samples from 85 plants in this study. The distribution of the three viruses within individual plants showed some differences, particularly between SqVYV and $\mathrm{CuLCrV}$, and these differences have practical implications for

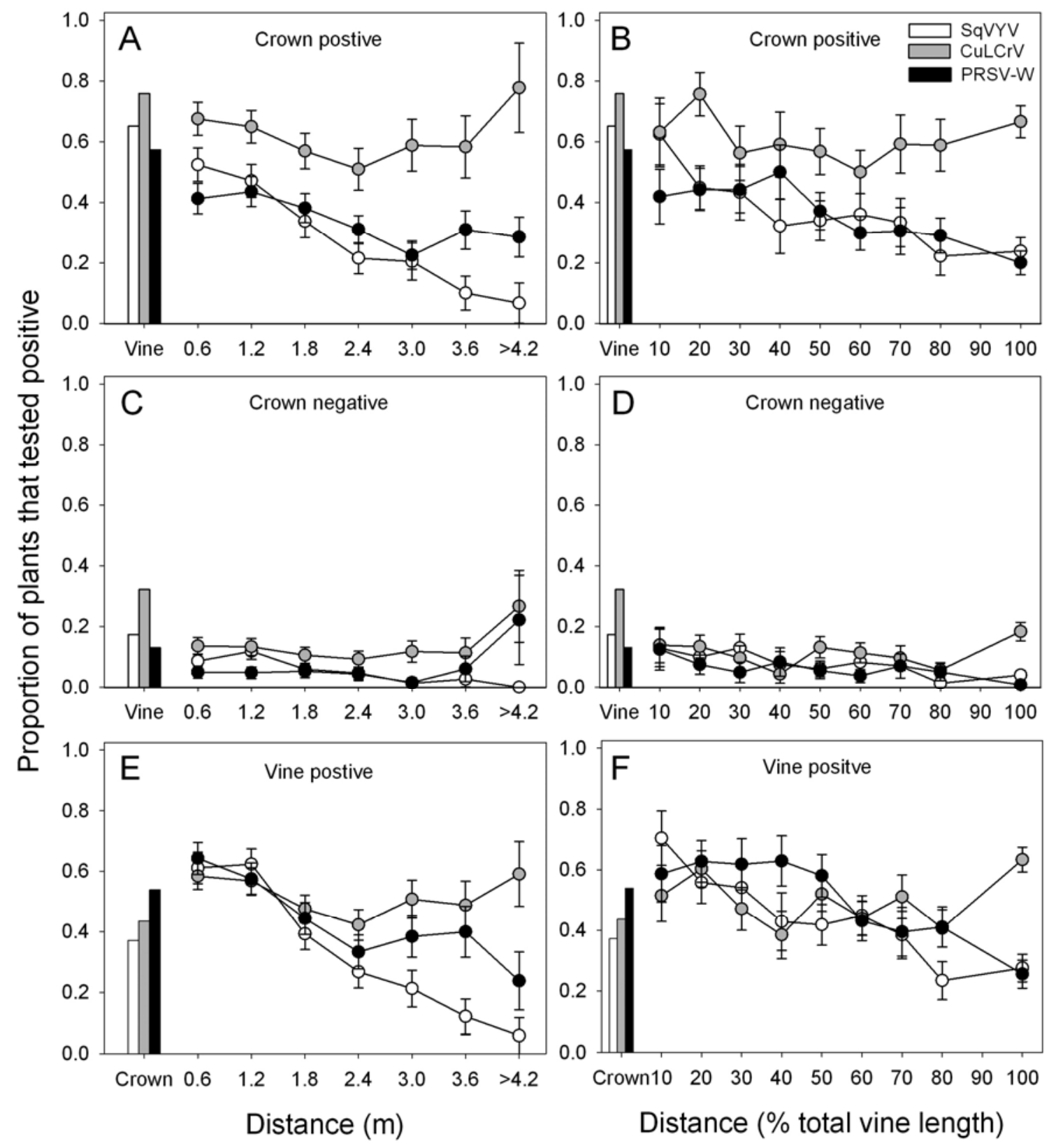

Fig. 4. Mean incidence and standard errors of Squash vein yellowing virus (SqVYV, white bar), Cucurbit leaf crumple virus (CuLCrV, gray bar), and Papaya ringspot virus type $\mathrm{W}$ (PRSV-W, black bar) in vine tissue at $\mathbf{A}, \mathbf{C}$, and $\mathbf{E}$, the measured distance or $\mathbf{B}, \mathbf{D}$, and $\mathbf{F}$, the percentage distance from the crown from watermelon plants that $\mathbf{A}$ and $\mathbf{B}$, tested positive for the specified virus in the crown; $\mathbf{C}$ and $\mathbf{D}$, tested negative for the specified virus in the crown; or $\mathbf{E}$ and $\mathbf{F}$, tested positive for the specified virus in vine tissue (i.e., a vine was rated positive if any of the vine segments tested positive). Bars represent the proportion of vines that tested positive in $\mathbf{A}$ and $\mathbf{B}$, crown-positive or $\mathbf{C}$ and $\mathbf{D}$, crown-negative plants or $\mathbf{E}$ and $\mathbf{F}$, the incidence of positive crowns from plants with at least one positive vine. Data were obtained from 80 plants collected in a commercial production field located near Immokalee, FL in 2007 and represent means and standard errors from four sampling dates. Sampling dates were 11 April, 18 April, 26 April, and 3 May 2007. 
sampling and detection. All three viruses were, in general, readily detectable at the base of the vine and in crown tissue. The ability to detect SqVYV in vine tissue decreased with increasing distance from the crown. The crown tissue has been considered the "gold standard" tissue for testing of SqVYV (2). However, our results showed that vine tissue or peduncles (or fruit) may test positive in the absence of a positive test of the crown and, therefore, a negative test of the crown should not be interpreted as a definitive negative diagnosis for the plant being tested. When testing for $\mathrm{CuLCrV}$, the tissue that provided the highest probability for detection was the tip of the vine, particularly for symptomatic plants; but, again, other tissues may test positive before the tip of the vine. PRSV-W exhibited similar distribution characteristics to SqVYV in that the incidence of vine sections that tested positive for each of these two viruses tended to decrease with increasing distance from the crown along the vines. Thus, crown tissue may be the best tissue to begin testing for PRSV-W. The advantage of testing the crown versus vines or fruit was emphasized in the
Duette site, where crowns of all five plants tested positive, regardless of the virus.

At the Duette site, the position of fruit along the watermelon vine was marked in an effort to ascertain whether large fruit served as a sink for virus because fruit are known to accumulate photosynthates (27). For SqVYV, it was possible to find infected watermelon crown, peduncle, and fruit tissue while having none or very few vine segments test positive. This result is in agreement with our previous detection of SqVYV preferentially in watermelon crown, peduncle, and fruit tissue. On the other hand, plants with $\mathrm{CuLCrV}$ (e.g., plants 4 and 5) show virus widely distributed throughout the plant; thus, detection is possible in almost any tissue. PRSV-W was not detected in peduncles or fruit of the Duette samples although it was found in the peduncles in the Immokalee survey, perhaps reflecting environmental or seasonal differences between the two sites (Duette samples were collected in the fall whereas Immokalee samples were collected in the spring) or plant growth stage effects. Overall, it did not appear

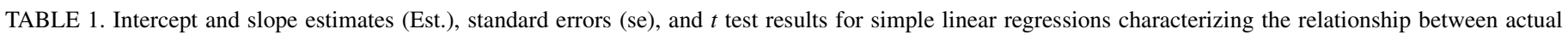

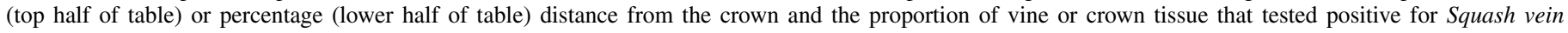

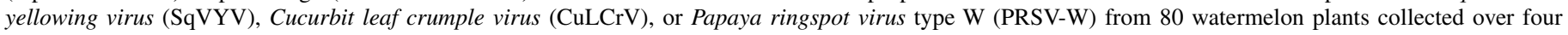
sampling dates in a commercial production field located near Immokalee, FL in 2007a

\begin{tabular}{|c|c|c|c|c|c|c|c|c|c|c|c|}
\hline \multirow[b]{2}{*}{ Tissue $^{b}$} & \multirow[b]{2}{*}{ Virus } & \multirow[b]{2}{*}{ Figure $^{c}$} & \multirow[b]{2}{*}{$R^{2}$} & \multicolumn{4}{|c|}{ Intercept } & \multicolumn{4}{|c|}{ Slope } \\
\hline & & & & Est. & se & $t$ & $P$ & Est. & $\mathrm{se}$ & $t$ & $P$ \\
\hline \multicolumn{12}{|l|}{ Actual } \\
\hline Crown (+) & SqVYV & $4 \mathrm{~A}$ & 0.97 & 0.596 & 0.031 & 19.43 & 0.000 & -0.132 & 0.011 & -11.72 & 0.000 \\
\hline Crown $(+)$ & CuLCrV & $4 \mathrm{~A}$ & 0.03 & 0.595 & 0.080 & 7.44 & 0.001 & 0.011 & 0.029 & 0.38 & 0.717 \\
\hline Crown (+) & PRSV-W & $4 \mathrm{~A}$ & 0.65 & 0.450 & 0.041 & 10.96 & 0.000 & -0.046 & 0.015 & -3.07 & 0.028 \\
\hline Crown (-) & SqVYV & $4 \mathrm{C}$ & 0.81 & 0.120 & 0.017 & 7.14 & 0.001 & -0.029 & 0.006 & -4.65 & 0.006 \\
\hline Crown (-) & CuLCrV & $4 \mathrm{C}$ & 0.23 & 0.085 & 0.048 & 1.80 & 0.132 & 0.021 & 0.018 & 1.22 & 0.277 \\
\hline Crown (-) & PRSV-W & $4 \mathrm{C}$ & 0.32 & -0.002 & 0.052 & -0.03 & 0.974 & 0.030 & 0.019 & 1.55 & 0.182 \\
\hline Vine $(+)$ & SqVYV & $4 \mathrm{E}$ & 0.95 & 0.733 & 0.047 & 15.60 & 0.000 & -0.167 & 0.017 & -9.66 & 0.000 \\
\hline Vine (+) & CuLCrV & $4 \mathrm{E}$ & 0.02 & 0.535 & 0.058 & 9.20 & 0.000 & -0.006 & 0.021 & -0.30 & 0.779 \\
\hline Vine (+) & PRSV-W & $4 \mathrm{E}$ & 0.81 & 0.663 & 0.055 & 11.98 & 0.000 & -0.095 & 0.020 & -4.68 & 0.005 \\
\hline \multicolumn{12}{|l|}{ Percent } \\
\hline Crown (+) & SqVYV & $4 B$ & 0.77 & 0.556 & 0.044 & 12.77 & 0.000 & -0.366 & 0.075 & -4.88 & 0.002 \\
\hline Crown (+) & CuLCrV & $4 B$ & 0.04 & 0.631 & 0.053 & 11.82 & 0.000 & -0.049 & 0.092 & -0.53 & 0.612 \\
\hline Crown (+) & PRSV-W & $4 B$ & 0.76 & 0.509 & 0.035 & 14.57 & 0.000 & -0.286 & 0.060 & -4.76 & 0.002 \\
\hline Crown (-) & SqVYV & 4D & 0.73 & 0.135 & 0.015 & 8.92 & 0.000 & -0.112 & 0.026 & -4.29 & 0.004 \\
\hline Crown (-) & CuLCrV & $4 \mathrm{D}$ & 0.05 & 0.104 & 0.032 & 3.22 & 0.015 & 0.013 & 0.055 & 0.23 & 0.822 \\
\hline Crown (-) & PRSV-W & 4D & 0.61 & 0.106 & 0.015 & 6.93 & 0.000 & -0.087 & 0.026 & -3.32 & 0.013 \\
\hline Vine $(+)$ & SqVYV & $4 \mathrm{~F}$ & 0.86 & 0.677 & 0.040 & 16.81 & 0.000 & -0.456 & 0.069 & -6.59 & 0.000 \\
\hline Vine (+) & $\mathrm{CuLCrV}$ & $4 \mathrm{~F}$ & 0.60 & 0.486 & 0.062 & 7.82 & 0.000 & 0.022 & 0.107 & 0.21 & 0.840 \\
\hline Vine $(+)$ & PRSV-W & $4 \mathrm{~F}$ & 0.83 & 0.716 & 0.041 & 17.17 & 0.000 & -0.416 & 0.072 & -5.80 & 0.001 \\
\hline
\end{tabular}

a Sampling dates were 11 April, 18 April, 26 April, and 3 May 2007.

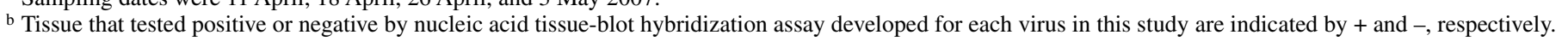

c Regression results correspond to the data shown in the Figure 4 plot listed.
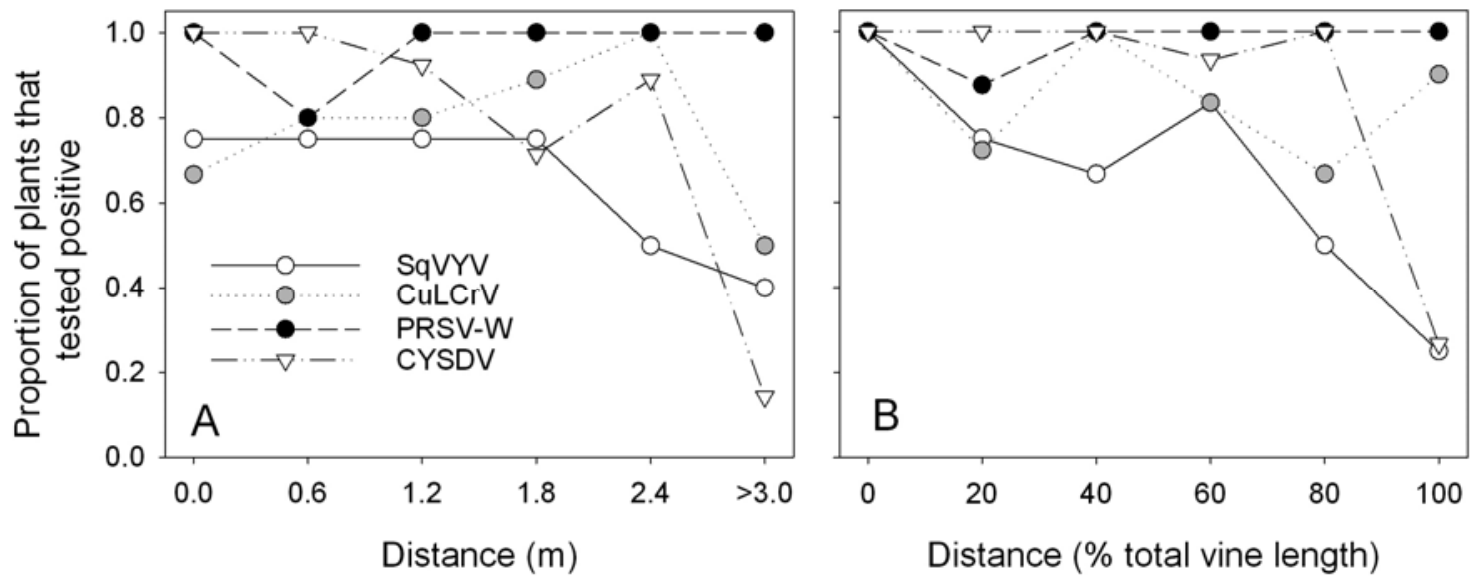

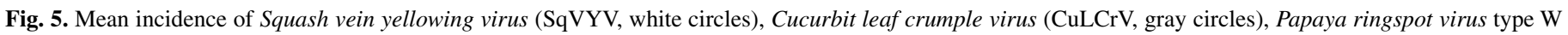

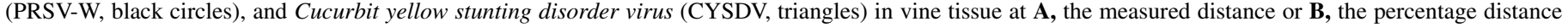

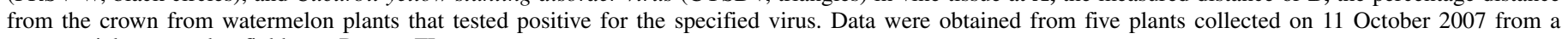
commercial watermelon field near Duette, FL. 
that the distribution of SqVYV, CuLCrV, or PRSV-W between or within vines was influenced by the location of the fruit in the Duette portion of this study.

Our current finding of watermelon crown, peduncle, and fruit tissue tending to be the tissues where SqVYV is most readily detectable is in contrast to the absence of a specific tissue tropism reported for closely related CVYV in cucumber, melon, and squash plants by Rubio and colleagues (26). This may be a reflection of the difference between how infected plants were produced in the two studies-field-grown, older plants inoculated by insect vectors in this study versus greenhouse-grown, younger plants (first-true-leaf stage) that were mechanically inoculated in the study of Rubio et al. (26). It may also reflect different types of virus-plant interactions for SqVYV and CVYV. For instance, watermelon plants are significantly impacted by SqVYV infection and generally die within 2 to 5 weeks of infection (depending upon a variety of host and environmental factors) (2), whereas none of the cucurbits analyzed by Rubio and colleagues (26) are killed by CVYV. This difference may have an effect on the distribution of the respective virus within the plant. Furthermore, no mention is made of mixed infections in the CVYV work (26), whereas mixed infections were common in the plants tested in this study. Whether the distribution of SqVYV in watermelon observed in our study was influenced by the presence of $\mathrm{CuLCrV}$,

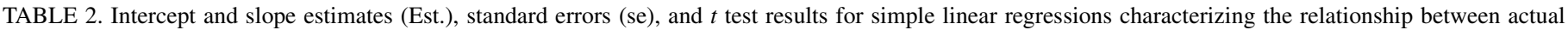

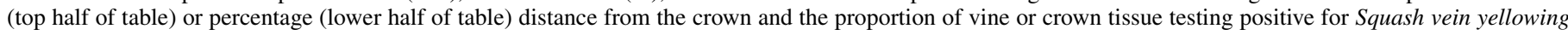

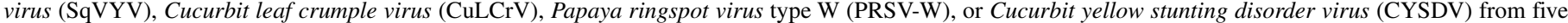
watermelon plants collected in a commercial production field located near Duette, FL in 2007a

\begin{tabular}{|c|c|c|c|c|c|c|c|c|c|c|}
\hline \multirow[b]{2}{*}{ Tissue $^{b}$} & \multirow[b]{2}{*}{ Virus } & \multirow[b]{2}{*}{$R^{2}$} & \multicolumn{4}{|c|}{ Intercept } & \multicolumn{4}{|c|}{ Slope } \\
\hline & & & Est. & se & $t$ & $P$ & Est. & se & $t$ & $P$ \\
\hline \multicolumn{11}{|l|}{ Actual } \\
\hline Vine (+) & SqVYV & 0.71 & 0.829 & 0.068 & 12.1 & 0.000 & -0.117 & 0.037 & -3.16 & 0.034 \\
\hline Vine (+) & CuLCrV & 0.20 & 0.786 & 0.141 & 5.57 & 0.005 & -0.007 & 0.046 & -0.09 & 0.934 \\
\hline Vine (+) & PRSV-W & 0.15 & 0.924 & 0.061 & 15.2 & 0.000 & 0.028 & 0.033 & 0.85 & 0.441 \\
\hline Vine $(+)$ & CYSDV & 0.62 & 1.123 & 0.164 & 6.83 & 0.002 & -0.226 & 0.089 & -2.54 & 0.064 \\
\hline \multicolumn{11}{|l|}{ Percent } \\
\hline Vine (+) & SqVYV & 0.77 & 0.976 & 0.102 & 9.60 & 0.001 & -0.619 & 0.168 & -3.69 & 0.021 \\
\hline Vine $(+)$ & CuLCrV & 0.10 & 0.913 & 0.107 & 8.52 & 0.001 & -0.119 & 0.177 & -0.67 & 0.538 \\
\hline Vine $(+)$ & PRSV-W & 0.15 & 0.953 & 0.038 & 25.1 & 0.000 & 0.054 & 0.063 & 0.85 & 0.441 \\
\hline Vine (+) & CYSDV & 0.46 & 1.133 & 0.176 & 6.44 & 0.003 & -0.533 & 0.291 & -1.84 & 0.140 \\
\hline
\end{tabular}

a Sampling date was 11 October 2007.

b Tissue that tested positive or negative by nucleic acid tissue blot hybridization assay developed for each virus in this study are indicated by + and - , respectively.

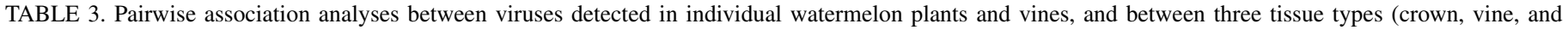
fruit) for four individual viruses ${ }^{\mathrm{a}}$

\begin{tabular}{|c|c|c|c|c|c|c|c|c|c|c|c|}
\hline \multirow[b]{2}{*}{ Tissue, virus } & \multirow[b]{2}{*}{ Comparison $^{\mathrm{b}}$} & \multirow[b]{2}{*}{$J$} & \multicolumn{6}{|c|}{ Jaccard analysis $^{\mathrm{c}}$} & \multicolumn{3}{|c|}{$\chi^{2}$ analysis $^{\mathrm{d}}$} \\
\hline & & & $s_{J}$ & $\mathrm{E}(J)$ & $Z$ & $P$ & $\operatorname{Max} J$ & $\operatorname{Min} J$ & $\chi^{2}$ & Sig & $V^{2}$ \\
\hline \multicolumn{12}{|l|}{ In plants } \\
\hline \multirow[t]{3}{*}{ Crown and vine } & SqVYV-CuLCrV & 0.73 & 0.055 & 0.55 & 3.20 & 0.001 & 0.87 & 0.42 & 17.77 & 0.000 & 0.22 \\
\hline & SqVYV-PRSV-W & 0.58 & 0.058 & 0.57 & 0.20 & 0.419 & 0.83 & 0.46 & 0.13 & 0.723 & 0.00 \\
\hline & CuLCrV-PRSV-W & 0.64 & 0.055 & 0.64 & 0.02 & 0.493 & 0.95 & 0.56 & 0.02 & 0.895 & 0.00 \\
\hline \multirow[t]{3}{*}{ Crown only } & SqVYV-CuLCrV & 0.40 & 0.074 & 0.26 & 1.94 & 0.026 & 0.85 & 0.00 & 6.41 & 0.011 & 0.08 \\
\hline & SqVYV-PRSV-W & 0.29 & 0.062 & 0.28 & 0.15 & 0.439 & 0.69 & 0.00 & 0.03 & 0.857 & 0.00 \\
\hline & CuLCrV-PRSV-W & 0.36 & 0.065 & 0.32 & 0.58 & 0.281 & 0.81 & 0.00 & 0.60 & 0.438 & 0.01 \\
\hline \multirow[t]{3}{*}{ Vine only } & SqVYV-CuLCrV & 0.66 & 0.061 & 0.47 & 3.02 & 0.001 & 0.71 & 0.26 & 17.87 & 0.000 & 0.23 \\
\hline & SqVYV-PRSV-W & 0.46 & 0.067 & 0.37 & 1.31 & 0.096 & 0.98 & 0.04 & 2.78 & 0.095 & 0.04 \\
\hline & CuLCrV-PRSV-W & 0.52 & 0.062 & 0.46 & 0.89 & 0.187 & 0.69 & 0.25 & 1.95 & 0.163 & 0.03 \\
\hline \multirow[t]{3}{*}{ In vines } & SqVYV-CuLCrV & 0.50 & 0.042 & 0.31 & 4.56 & 0.000 & 0.72 & 0.00 & 33.94 & 0.000 & 0.16 \\
\hline & SqVYV-PRSV-W & 0.38 & 0.044 & 0.24 & 3.19 & 0.001 & 0.94 & 0.00 & 15.39 & 0.000 & 0.07 \\
\hline & CuLCrV-PRSV-W & 0.43 & 0.041 & 0.29 & 3.26 & 0.001 & 0.68 & 0.00 & 17.23 & 0.000 & 0.08 \\
\hline \multirow[t]{3}{*}{ In vine segments } & SqVYV-CuLCrV & 0.22 & 0.020 & 0.12 & 5.06 & 0.000 & 0.61 & 0.00 & 46.60 & 0.000 & 0.04 \\
\hline & SqVYV-PRSV-W & 0.17 & 0.019 & 0.11 & 3.22 & 0.001 & 0.85 & 0.00 & 17.07 & 0.000 & 0.01 \\
\hline & CuLCrV-PRSV-W & 0.16 & 0.016 & 0.14 & 1.47 & 0.070 & 0.72 & 0.00 & 2.88 & 0.089 & 0.00 \\
\hline \multirow[t]{3}{*}{ SqVYV } & Crown-vine & 0.59 & 0.075 & 0.28 & 4.12 & 0.000 & 0.71 & 0.00 & 23.36 & 0.000 & 0.31 \\
\hline & Crown-peduncle & 0.34 & 0.082 & 0.23 & 1.43 & 0.077 & 0.96 & 0.00 & 4.34 & 0.037 & 0.06 \\
\hline & Vine-peduncle & 0.38 & 0.076 & 0.27 & 1.43 & 0.076 & 0.71 & 0.00 & 3.47 & 0.063 & 0.05 \\
\hline \multirow[t]{3}{*}{ CuLCrV } & Crown-vine & 0.60 & 0.066 & 0.38 & 3.23 & 0.001 & 0.60 & 0.14 & 19.64 & 0.000 & 0.26 \\
\hline & Crown-peduncle & 0.50 & 0.081 & 0.29 & 2.62 & 0.004 & 0.94 & 0.00 & 11.14 & 0.001 & 0.16 \\
\hline & Vine-peduncle & 0.59 & 0.070 & 0.40 & 2.67 & 0.004 & 0.62 & 0.01 & 14.06 & 0.000 & 0.21 \\
\hline \multirow[t]{3}{*}{ PRSV-W } & Crown-vine & 0.68 & 0.069 & 0.37 & 4.57 & 0.000 & 0.97 & 0.00 & 26.92 & 0.000 & 0.36 \\
\hline & Crown-peduncle & 0.38 & 0.071 & 0.35 & 0.36 & 0.358 & 1.00 & 0.00 & 0.93 & 0.335 & 0.01 \\
\hline & Vine-peduncle & 0.35 & 0.069 & 0.34 & 0.09 & 0.462 & 0.94 & 0.00 & 0.06 & 0.800 & 0.00 \\
\hline
\end{tabular}

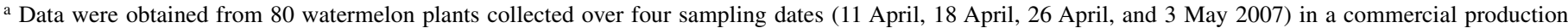
field located near Immokalee, FL.

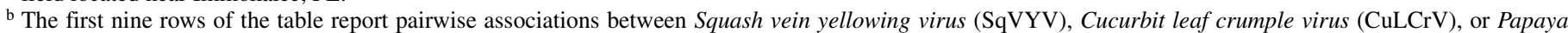
ringspot virus type W (PRSV-W) at the plant level where a plant was rated as infected if the crown, vine tissue, or both tissues tested positive. The next six rows report association between viruses at the level of individual vines or vine sections. The final rows of the table report association of viruses within individual vines.

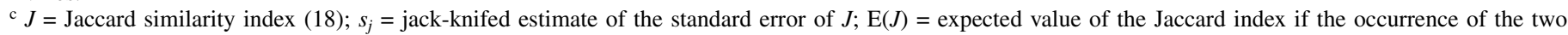
viruses was not associated; $P=$ probability that $J$ is significantly different than $\mathrm{E}(J)$ according to a $Z$ test (29); Max $J=$ maximum value of $J$ for the given data set; $\operatorname{Min} J=$ minimum value of $J$ for the given data set.

d Cramer's $V^{2}(13)$ ranges from 0 to 1 , where 1 represents a perfect association. 
PRSV-W, or CYSDV remains to be tested. Inoculations of other vining cucurbits with SqVYV may shed further light on the virus-plant interactions.

The distribution of viruses among and within individual plants and the degree of association between them can be used to formulate hypotheses on the vector acquisition and transmission processes. There were significant pairwise associations between SqVYV and CuLCrV at the plant level, as well as at the vine and vine-segment levels, but the degree of association relative to the maximum level of association was higher at the plant and vine level than at the vine-segment level (Table 3). This result is consistent with the observed spatial distribution of these viruses within plants. At the plant scale, significant association can be expected between viruses that can be acquired and transmitted by the same insect species regardless of whether the viruses were acquired from outside or within the planting. For example, significant associations were found using the same statistical approach for the two Carlavirus spp. Hop latent virus (HpLV) and Hop mosaic virus (HpMV), initially suspected (22) and later confirmed (10) of being vectored by the same aphid species. If, however, the viruses cannot be acquired or transmitted by the same individual vector (e.g., the acquisition of one of the viruses prevents the acquisition of the other), these associations may still arise if an immigrating population of vectors originated from an area that harbored both viruses (e.g., an earlier planting, or a field that harbored weed hosts of both viruses) and the vectors showed an affinity for the same individual plant. Mixed SqVYV and $\mathrm{CuLCrV}$ infections of several common cucurbit weed reservoir hosts, including Balsam-apple (Momordica charantia L.) and smellmelon (Cucumis melo L. var. dudaim (L.) Naud.), have been previously detected $(3,4)$. Detailed studies to determine whether single whiteflies can acquire and transmit both viruses simultaneously are needed to fully understand the nature of these associations.

The relationship between the aphid-transmitted PRSV-W and the whitefly-transmitted viruses is a bit more speculative than the relationship between viruses transmitted by the same vector. At the plant level (vines or vine segments tested on a plant), there was no indication of association between PRSV-W and either SqVYV and CuLCrV, which would be expected given independent transmission of the viruses to the target plants. This was shown to be the case in hop between the two Carlavirus spp. $\mathrm{HpLV}$ and HpMV and the Ilarvirus sp. Apple mosaic virus (22). In the current study, however, PRSV-W showed a significant levels of association with SqVYV and CuLCrV at the scales of the individual vine or vine segment levels, despite the smaller value of the index relative to the plant level. Thus, even though the number of plants showing mixed infections with PRSV-W in this study did not deviate from what would be expected under the null hypothesis of "no association," the number of vines and vine segments that had mixed infections was higher than expected, resulting in significant associations. This type of relationship (i.e., where significant associations exist at lower spatial scales but not higher scales) might result if the viruses show an affinity for each other during replication or movement in infected plants. The statistical significance at the vine and vine segment scales may also be an artifact of a larger sample size and, thus, a smaller standard error. Additional studies are necessary to determine the mechanism that results in this type of relationship.

There is an abundance of literature reporting on the dynamics of viral titer in mixed viral infections for a variety of pathosystems, and an earlier report by Zhang et al. (31) provides a general overview. Many of these studies were based on laboratory experiments because of the difficulties in controlling external factors in field experiments. In this study, viral titer was not measured because we had not yet developed quantitative tools for detecting SqVYV. The multiscale approach undertaken in this study gave a perspective on epidemic development that was different from studies that used a titer-based approach. Measurements at the plant scale provide insight into the virus transmission process. Measurements at the vine and vine-segment levels provide insight into the affinity of viruses for each other inside the host, and offer an indirect measure of titer at the plant level. This information, collected from naturally occurring epidemics, not only allowed us to formulate hypotheses on the transmission process but also gave the information necessary to refine sampling protocols that can be used as part of an early detection program for these viruses. Symptoms induced by SqVYV are ultimately diagnostic in watermelon within weeks of the earliest symptoms due to the obvious vine decline and plant death (2). However, the sampling techniques and tissue-blot nucleic acid hybridization assays described here will be extremely useful tools for confirmation of virus identity and further epidemiological and biological characterization of all four viruses and the diseases they cause.

\section{ACKNOWLEDGMENTS}

Financial support was provided in part by USDA-ARS CRIS project 6618-22000-026-00D and USDA CSREES SCRI grant 2008-04890. We thank C. Vanderspool and G. Hess for excellent technical assistance; and T. Barfield, J. Barfield, L. Moss, W. Roan, and L. Lucas for their donation of plants and discussions about cucurbit virus management.

\section{LITERATURE CITED}

1. Adkins, S., Polston, J. E., and Turechek, W. W. 2009. Cucurbit leaf crumple virus identified in common bean in Florida. Plant Dis. 93:320.

2. Adkins, S., Webb, S. E., Achor, D., Roberts, P. D., and Baker, C. A. 2007. Identification and characterization of a novel whitefly-transmitted member of the family Potyviridae isolated from cucurbits in Florida. Phytopathology 97:145-154.

3. Adkins, S., Webb, S. E., Baker, C. A., and Kousik, C. S. 2008. Squash vein yellowing virus detection using nested polymerase chain reaction demonstrates that the cucurbit weed Momordica charantia is a reservoir host. Plant Dis. 92:1119-1123.

4. Adkins, S., Webster, C. G., Baker, C. A., Weaver, R., Rosskopf, E. N., and Turechek, W. W. 2009. Detection of three whitefly-transmitted viruses infecting the cucurbit weed, Cucumis melo var. dudaim, in Florida. Plant Health Progress doi:10.1094/PHP-2009-1118-01-BR.

5. Akad, F., Webb, S., Nyoike, W., Liburd, O. E., Turechek, W., Adkins, S., and Polston, J. E. 2008. Detection of Cucurbit leaf crumple virus in Florida cucurbits. Plant Dis. 92:648.

6. Berdiales, B., Bernal, J. J., Saez, E., Woudt, B., Beitia, F., and Rodriguez Cerezo, E. 1999. Occurrence of cucurbit yellow stunting disorder virus (CYSDV) and beet pseudo-yellows virus in cucurbit crops in Spain and transmission of CYSDV by two biotypes of Bemisia tabaci. Eur. J. Plant Pathol. 105:211-215.

7. Bertelsen, D., Harwood, J., Hoff, F., Lee, H., Perez, A., Pollack, S., and Somwaru, A., and Zepp, G. 1994. Watermelons: an economic assessment of the feasibility of providing multiple-peril crop insurance. Prepared by the Economic Research Service, USDA in cooperation with the University of California for the Federal Crop Insurance Corporation. http://www.rma.usda.gov/pilots/feasible/PDF/wtrmelon.pdf

8. Brown, J. K., Guerrero, J. C., Matheron, M., Olsen, M., and Idris, A. M. 2007. Widespread outbreak of Cucurbit yellow stunting disorder virus in melon, squash, and watermelon crops in the Sonoran desert of Arizona and Sonora, Mexico. Plant Dis. 91:773.

9. Brown, J. K., Idris, A. M., Alteri, C., and Stenger, D. C. 2002. Emergence of a new cucurbit-infecting begomovirus species capable of forming viable reassortants with related viruses in the Squash leaf curl virus cluster. Phytopathology 92:734-742.

10. Crowle, D. R., Pethybridge, S. J., and Wilson, C. R. 2006. Transmission of hop latent and hop mosaic carlaviruses by Macrosiphum euphoribae and Myzus persicae. J. Phytopathol. 154:745-747.

11. Dennehy, T. J., DeGain, B. A., Harpold, V. S., Brown, J. K., Morin, S., Fabrick, J. A., Byrne, F. J., and Nichols, R. L. 2006. New challenges to management of whitefly resistance to insecticides in Arizona. Univ. Ariz. College Agric. 2005 Veg. Rep. Ser. P-144.

12. Egel, D. S., and Adkins, S. 2007. Squash vein yellowing virus identified in watermelon (Citrullus lanatus) in Indiana. Plant Dis. 91:1056.

13. Gibbons, J. D. 1985. Nonparametric Methods for Quantitative Analysis, 2nd ed. American Sciences Press, Inc., Columbus, $\mathrm{OH}$. 
14. Guzman, P., Sudarshana, M. R., Seo, Y.-S., Rojas, M. R., Natwick, E., Turini, T., Mayberry, K., and Gilbertson, R. L. 2000. A new bipartite geminivirus (begomovirus) causing leaf curl and crumpling in cucurbits in the Imperial Valley of California. Plant Dis. 84:488.

15. Huber, M. 2006. Taking vital vines. Citrus Veg. Mag. 70:22-24.

16. Kao, J., Jia, L., Tian, T., Rubio, L., and Falk, B. W. 2000. First report of Cucurbit yellow stunting disorder virus (genus Crinivirus) in North America. Plant Dis. 84:101.

17. Kou, Y.-W., Rojas, M. R., Gilbertson, R. L., and Wintermantel, W. M. 2007. First report of Cucurbit yellow stunting disorder virus in California and Arizona, in association with Cucurbit leaf crumple virus and Squash leaf curl virus. Plant Dis. 91:330.

18. Ludwig, J. A., and Reynolds, J. F. 1988. Statistical Ecology. John Wiley \& Sons, New York.

19. Manly, B. F. J. 1997. Randomization, Bootstrap and Monte Carlo Methods in Biology, 2nd ed. Chapman \& Hall, London.

20. Matthews, R. E. F. 1992. Fundamentals of Plant Virology. Academic Press, Inc., San Diego, CA.

21. McGrath, M. T. 2004. Diseases of cucurbits and their management. Pages 455-510 in: Diseases of Fruits and Vegetables: Diagnosis and management, Vol. 1. S. A. M. H Naqvi, ed. Kluwer Publishers, Dordrecht, The Netherlands.

22. Pethybridge, S. J., and Turechek, W. W. 2003. Analysis of the association among three viruses infecting hop in Australia. Plant Pathol. 52:158-167.

23. Polston, J. E., Hladky, L. L., Akad, F., and Wintermantel, W. M. 2008. First report of Cucurbit yellow stunting disorder virus in cucurbits in
Florida. Plant Dis. 92:1251.

24. Rojas, M. R., Gilbertson, R. L., Russell, D. R., and Maxwell, D. P. 1993. Use of degenerate primers in the polymerase chain reaction to detect whitefly-transmitted geminiviruses. Plant Dis. 77:340-347.

25. Rubio, L., Abou-Jawdah, Y., Lin, H.-X., and Falk, B. W. 2001. Geographically distant isolates of the crinivirus Cucurbit yellow stunting disorder virus show very low genetic diversity in the coat protein gene. J. Gen. Virol. 82:929-933.

26. Rubio, L., Janssen, D., Cuadrado, I. M., Moreno, P., and Guerri, J. 2003. Rapid detection of Cucumber vein yellowing virus by tissue-print hybridisation with digoxigenin-labelled cDNA probes. J. Virol. Methods 114:105-107.

27. Salisbury, F. B., and Ross, C. W. 1992. Plant Physiology. Wadsworth Publishing Company, Belmont, CA.

28. Schuster, D. J., Stansly, P. A., Polston, J. E., Gilreath, P. R., and McAvoy, E. 2007. Management of whiteflies, whitefly-vectored plant virus, and insecticide resistance for vegetable production in southern Florida. IFAS Ext. Publ. ENY-735. http://edis.ifas.ufl.edu/pdffiles/IN/IN69500.pdf

29. Turechek, W. W., and Madden, L. V. 2000. Analysis of the association between the incidence of two spatially aggregated foliar diseases of strawberry. Phytopathology 90:157-170.

30. Wyatt, S. D., and Brown, J. K. 1996. Detection of subgroup III geminivirus isolates in leaf extracts by degenerate primers and polymerase chain reaction. Phytopathology 86:1288-1293.

31. Zhang, X.-S., Holt, J., and Colvin, J. 2001. Synergism between plant viruses: A mathematical analysis of the epidemiological implications. Plant Pathol. 50:732-746. 